\title{
EFFECT OF MATERNAL AGE ON FETAL WEIGHT
}

\author{
Sadikchya Singh Rana ${ }^{1}$ \\ ${ }^{1}$ Dept. of Obs and Gynae. Shree Birendra Hospital
}

\begin{abstract}
Introduction: Teenage childbearing is linked to a host of negative social, economic and medical consequences for both mother and child. Maternal mortality among girls under 18 years is two to five times higher than that of women in their 20s. This study was conducted to determine the relationship between maternal age on fetal weight.
\end{abstract}

Method: It was a prospective, hospital based study, carried out in 491 primi gravidas with fullterm singleton pregnancy. The study population was divided into two groups, women who were 19 and less than 19 years of age and women who were more than 19 years of age. Fetal weight as the outcome variable was compared between these groups.

Results: The age of the mother ranged from 16 to 37 years. $24.8 \%$ women in the study population were $<19$ years of age. Although the difference was not clinically significant $(p=0.51), 1 / 3^{\text {rd }}$ of the mothers who were $<19$ had low birth weight.

Conclusion: the relation of low birth weight and young maternal age could not be proven in this study.

Key Words: age, fetal weight, maternal age.

\section{INTRODUCTION}

Teenage pregnancy and childbearing have become pressing social concerns in the world. Research has shown that teenage childbearing is linked with negative social, economic and medical consequences for both mother and child. There is a great deal of debate, however, whether these consequences are due to maternal age per se, or whether they are caused by the adverse economic and social circumstances of teenagers who become mothers.

The World Health Organization (WHO) stressed that acceptable progress to reduce maternal and perinatal mortality will not be realized until the governments make a full commitment to lower maternal deaths. About 529 000 women in the world die each year from pregnancy- related causes-and almost half of these deaths occur in the Western Pacific and South-East Asia Regions. Maternal mortality among girls under 18 years is two to five times higher than that of women in their 20s.

In the South-East Asian Region, the child-bearing rate among adolescents aged 15 to 19 years ranges from 146 live births per 1000 women in Bangladesh to 26 per 1000 in the Republic of Korea.

There are studies from third world countries mentioning the relation between LBW and the maternal age. Although, we have high incidence of adolescent mother, in our country no such research have been done. This study was conducted to find correlation between maternal age and LBW.

\author{
Correspondence: \\ Dr. Sadhikchya Singa Rana \\ Department of Obst Gyanacoloy, Shree Birendra Hospital. \\ E-mail: drssrana@gmail.com \\ Cell No.: 9851078400
}




\section{METHOD}

This was a Hospital based prospective comparative study done at Paropakar Maternity and Women's Hospital Thapathali, Kathmandu, Nepal. This study was conduced from $1^{\text {st }}$ Poush to $30^{\text {th }}$ Chaitra 2063 [16 ${ }^{\text {th }}$ December 2006 to $12^{\text {th }}$ April 2007]. The study population were all the primi gravidas who were admitted with full term pregnancy. Women who were 19 years and below were considered young primi. There were total of 7627 obstetric admissions in the study period out of which there were 2693 primi gravidas. Five hundred pregnant women were enrolled for the study as per inclusion and exclusion criteria. All the primi patients admitted in the hospital with term and Singleton pregnancy were included in the study. Multigravidae, patients with anaemia, Twin or multiple pregnancies, Stillbirths and patients not willing to participate in the study were excluded. Permission of the hospital was taken before the study began.

Questionnaire was filled at the admission room which included information regarding identification, age, residence, occupation, education, socio-economic status, any previous diseases. A full obstetric history including at menarche, menstrual cycles, last menstrual period, duration of marriage, gravida, para, number of antenatal visits (if they have done), iron intake was asked. The patient was examined generally and systemically. General examination included general condition, pallor, oedema, jaundice, pulse rate, blood pressure, height, weight, respiratory system, cardiovascular system followed by detail obstetric examination. The study population was divided into two groups, women more than 19 and less than 19 years of age. Then the patient was followed either in the labour room, operation theatre or ward. The weight of the baby was taken and recorded. Low birth weight was considered if birth weight was below $2500 \mathrm{gm}$.

The collected information was entered daily in the Master Chart. SPSS version 10 was used for calculations. Statistical analysis was done using Chi-square test and students t-test as applicable.

\section{RESULTS}

Although five hundred cases were initially enrolled in the study, only four hundred ninety one of them were finally analysed as six cases refused to take part in the study, two had still birth and one had undiagnosed twin pregnancy.

Majority of the mothers in the study population were between 19-24 years of age. Very few mothers were between 35-40 years of age. A total of 122 (24.8\%) patients were below the age of 19 years (Table 1 ).

Almost $1 / 3^{\text {rd }}$ of the mothers below the age of 19 had low birth weight. But the difference in fetal weight was not statistically significant $(P$ value $=0.51$ ) among the mothers who were more or less than 19 years of age (table 2 ).
Table 1.Maternal Age Distribution

\begin{tabular}{|c|c|c|}
\hline Age & No. of Patients & Percentage \\
\hline$<19$ & 122 & 24.8 \\
\hline $19-24$ & 293 & 59.7 \\
\hline $25-29$ & 61 & 12.4 \\
\hline $30-34$ & 12 & 2.4 \\
\hline $35-40$ & 3 & 0.6 \\
\hline Total & 491 & 100 \\
\hline
\end{tabular}

Table 2.Fetal Weight in Relation to Maternal Age

\begin{tabular}{|c|c|c|}
\hline Age & $\begin{array}{c}\text { Low Birth } \\
\text { weight(<2.5kg) }\end{array}$ & $\begin{array}{c}\text { Normal Birth } \\
\text { Weight(>2.5kg) }\end{array}$ \\
\hline$<19$ & 32 & 90 \\
\hline$>19$ & 86 & 283 \\
\hline Total & 118 & 373 \\
\hline
\end{tabular}

\section{DISCUSSION}

Over half of the world's population is below 25 years of age and more than $80 \%$ of the world's youth live in developing countries. In the mid-1990s, the global teenage population was estimated at 513 million.

In this study the youngest mother was 16 years of age and the eldest mother was 37 years of age. A total of 122 $(24.8 \%)$ women in the study population were $<19$ years of age (Table 1). Almost $1 / 3^{\text {rd }}$ of the mothers below the age of 19 had low birth weight. But the difference in fetal weight was not statistically significant $(P$ value $=0.51$ ) among the mothers who were more or less than 19 years of age (Table 2).

Similar to this study Reichman NE et al $^{1}$ reported the youngest (younger than 15) and oldest (aged 40 and older) mothers were only at higher risk to deliver a low-birthweight baby; older teenagers were not at any significantly increased risk to deliver a low-birth-weight baby than women aged 25-29. The seemingly poorer birth outcomes of teenage mothers appeared to result largely from their adverse socioeconomic circumstances, not from young maternal age.

But Hirve $\mathrm{SS}^{2}$ reported the unadjusted relative risks for LBW were significantly higher for maternal age less than 20 years $(R R=1.27)$.

Leppert PC et $\mathrm{al}^{3}$ also reported after comparing three birth outcomes, gestational age, birth weight, and type of delivery, among adolescent (13-19) and those over 20 years of age, that younger mothers were more likely than older ones to have babies 38 weeks gestation and weighing $2500 \mathrm{~g}$. He concluded that, even with similar 
comprehensive care, adolescent mothers in this study were at greater risk of adverse outcomes than older mothers. Briggs $\mathrm{MM}$ et $\mathrm{al}^{4}$ also reported adolescents (<19years of age) had significantly more low birth weight infants $(<2500 \mathrm{~g})$ than adults ( $>20$ years old) $(\mathrm{P}=0.008)$. Anemia is significant risk factor for poor obstetric outcomes and is potentially modifiable.

Similar analysis was done by Machedo $\mathrm{CJ}^{5}$ in a population based study on the impact of maternal age at first birth on low birth weight, preterm birth and low Apgar scores at one minute and at five minutes among live births delivered to primiparous on 73,820 birth records from the 1998 birth cohort Maternal ages below 20 and above 30 years were significantly associated with the risks of low birth weight and preterm birth, but no association was found between maternal ages and Apgar score. But this result seems to be inconsistent, low birth weight, preterm birth and low Apgar scores measure different dimensions of newborn well-being, and the association of each measure with maternal age is expected to diverge.

\section{CONCLUSION}

Although in this study, the effect of young maternal age on low birth weight could not be proven statistically we could see the high incidence of low birth weight in younger age group. Our study has several limitations including the sample size and considering only few variables. A detailed study with large sample size and correlation of other variables will be more appropriate. Eventhough the birth weight is less in young age group the difference is statistically not significant in our study.

\section{REFERENCES}

1. Reichman NE, Pagnini DL. Maternal Age and Birth Outcomes. Fam. Planning Perspect. 1997; 29(6):268-72.

2. Hirve SS, Ganatra BR., Determinants of Low Birth Weight: a community based prospective cohort study. Indian Pediatrics J. 1994;31(10):1221-5.

3. Leppert PC, Pregnancy Outcome among Adolescent and Older Women Receiving Comprehensive Prenatal Care. J of Adolescent health care. 1986;7(2);112-7.

4. Briggs $M M$, Hopman WM, Comparing Pregnancy in Adolescents and Adults: obstetric outcomes and prevalence of anemia. J Obstet Gynaecol Can. 2007;29(7):546-55.

5. Machedo CJ. Impact of Maternal Age on Birth Outcomes: A population based study of primiparous Brazilian women. Cambridge Journals. 2005;10:1017.

6. Rees JM, Lederman SA, Kiely JL. Birth weight associated with Lowest Neonatal Mortality: infants of adolescent and adult mothers. J of Pediatrics. 1996;98(6):61-8.

7. Strobino DM, Margaret E, Kim YJ, Nanda J. Mechanisms for Maternal Age Differences in Birth Weight. American Journal of Epidemiology. 1998; 142(5):504-14. 